\title{
Angiotensinogen localization and secretion in the rat pancreas
}

\author{
M Regoli, M Bendayan", L Fonzi, C Sernia ${ }^{2}$ and E Bertelli \\ Department of Anatomical and Biomedical Sciences, University of Siena, Via Aldo Moro 4, 53100 Siena, Italy \\ ${ }^{1}$ Department of Pathology and Cell Biology, University of Montreal, Montreal, Canada \\ ${ }^{2}$ Department of Physiology and Pharmacology, University of Queensland, Queensland 4072, Brisbane, Australia \\ (Requests for offprints should be addressed to E Bertelli; Email: bertelli5@unisi.it)
}

\begin{abstract}
Renin and angiotensinogen have been previously found in the rat pancreas, and angiotensin receptors have been located in the apical domain of duct cells. To evaluate the possibility that angiotensin II could be generated within the duct system, we decided to determine whether angiotensinogen is present in rat pancreatic juice and the angiotensinogen-immunoreactive pancreatic cell types that could be responsible for its production. Angiotensinogen was detected in significant amounts by Western blotting in pancreatic juice collected from several individual rats. Different isoforms between plasma and pancreatic juice angiotensinogens were demonstrated by isoelectric focusing. Immunocytochemical experiments revealed angiotensinogen-immunoreactive cells at the
\end{abstract}

periphery of the islets of Langerhans, and confocal microscopy demonstrated that most angiotensinogenimmunoreactive cells were glucagon-secreting cells. Secretion of angiotensinogen did not follow the regulated secretory pathway since it was absent from the glucagoncontaining granules. This was confirmed by electron microscopy immunocytochemistry. Duct and acinar cells did not express angiotensinogen at an immunocytochemical detectable level. The present findings indicated an exocrine secretion of angiotensinogen by glucagonsecreting cells and suggest that one of the final targets of the local pancreatic renin-angiotensin system may be the duct epithelium.

Journal of Endocrinology (2003) 179, 81-89

\section{Introduction}

The renin-angiotensin system (RAS) is a relatively simple cascade of enzymatic reactions that transforms a protein substrate, referred to as angiotensinogen (Agt or renin substrate), into the bioactive peptide angiotensin II (Ang II) (Peach 1977, Reid et al. 1978). Agt, a glycoprotein that displays a molecular weight ranging between 54 and $65 \mathrm{kDa}$ depending on animal species and different patterns of glycosylation (Reid et al. 1978, Tewksbury 1983), is secreted by hepatocytes into the blood and subsequently cleaved to generate des-angiotensin I-angiotensinogen and the decapeptide angiotensin I (Ang I) (Peach 1977, Reid et al. 1978). The enzyme responsible for this reaction is renin produced and secreted by the kidney, mainly by cells located within the tunica media of the glomerular afferent arteriole (Peach 1977, Hackenthal et al. 1990). A dipeptidyl carboxypeptidase, angiotensin-converting enzyme, primarily located in the pulmonary vascular endothelium, releases the Ang I carboxy-terminal dipeptide generating the octapeptide Ang II (Peach 1977, Reid et al. 1978). Further modifications can lead to the formation of other angiotensinogen-derived metabolites, all of them provided with biological activities. Among them are angiotensin
2-8, angiotensin 3-8 and angiotensin 1-7 (De Gaspero et al. 2000).

Ang II exerts its main action on vascular smooth muscle and adrenocortical cells, increasing vascular resistance and secretion of aldosterone respectively (Peach 1977, Reid et al. 1978). In addition, Ang II has been reported to increase catecholamine secretion from the adrenal medulla, to induce thirst, to stimulate the secretion of adrenocorticotrophin and vasopressin, and to increase blood pressure acting directly on the brain (Reid et al. 1978). Taken together, all these actions contribute to maintaining cardiovascular homeostasis by regulating blood pressure and the volume and composition of the extracellular fluid (Peach 1977).

Beside the classical circulating RAS that has the abovementioned systemic effects, various tissue or local RAS have been reported (Campbell 1987). In particular, local RAS components or tissue generation of Ang II have been detected in several organs such as brain (Phillips et al. 1993, Sernia 1995), pituitary (Thomas \& Sernia 1990a), adrenal glands (Vinson 1995, Mulrow \& Franco-Saenz 1996), heart (Dostal 2000), kidneys (Celio 1981, Hunt et al. 1992, Darby \& Sernia 1995), gonads (Thomas \& Sernia 1990b, Vinson et al. 1997) and pancreas 
(Leung et al. 1998, 1999, Tahmasebi et al. 1999, Leung \& Carlsson 2001). The role played by these tissue RAS is not well understood and they have been proposed to regulate local blood flow or to fulfil specific functions according to the tissue.

Data concerning local pancreatic RAS are controversial. Expression of pancreatic RAS has been reported in different sites according to animal species and/or to the techniques employed. For instance, Ang receptor 1 (AT1) was detected in pancreatic B cells in human tissue (Tahmasebi et al. 1999), throughout the entire pancreas in the dog (Chappell et al. 1992) and in the duct epithelium in rodent pancreas (Leung et al. 1997). Interestingly, in rat and mouse pancreas, AT1 as well as AT2 receptors have been assigned to the luminal side of the duct epithelium (Leung et al. 1997), raising the possibility that under particular circumstances Ang II or Ang-related peptides may be present in the lumen of the ducts. Thus, in the present study we decided to determine whether the molecular precursor of Ang II (i.e. Agt) could be detected in the pancreatic juice (PJ) and, if so, the Agt-immunoreactive cells that should be considered candidates for its secretion.

\section{Materials and Methods}

\section{Antibodies}

Rabbit anti-Agt antibody has been shown to react specifically with rat Agt with no cross-reaction with angiotensins or human and mouse Agt (Thomas \& Sernia 1988). Guinea pig anti-glucagon and anti-insulin antibodies were purchased from Peninsula Laboratories (San Carlos, CA, USA) and Zymed Laboratories (San Francisco, CA, USA) respectively. Donkey Rhodamin (TRITC)-conjugated anti-rabbit IgG and Fluorescein (FITC)-conjugated antiguinea pig IgG antibodies (both double-labelling grade) were purchased from Chemicon International (Temecula, CA, USA).

\section{Animals and surgical procedure}

A total of 14 adult male Sprague-Dawley rats (600 g) were used for this study. Animals were obtained from Charles River Italia (Calco, Lecco, Italy) and kept in the central housing facility of the University of Siena up to the date of the experiments. They were fed with a standard laboratory diet and had free access to tap water. Animals were fasted the night before the experiments. Eight animals were anaesthetized with an i.p. injection of pentobarbital $(40 \mathrm{mg} / \mathrm{kg})$. The bile duct was ligated and cannulated with a PE-10 polyethylene tube close to the hilus of the liver. Bile was drained via this cannula into an Eppendorf tube. The common bile duct was then ligated close to its duodenal ending and, after allowing the remaining bile to drain, cannulated with a second PE-10 polyethylene tube.
Fluid recovered from the latter cannula was assumed to be pure PJ, which was collected into an Eppendorf tube kept on ice. A mixture of antiproteases ( $1 \mathrm{mM}$ EDTA, $10 \mu \mathrm{g} /$ $\mathrm{ml}$ aprotinin, $1 \mathrm{mM}$ phenylmethylsulphonyl fluoride and $2 \mathrm{mM}$ benzamidine) was added to prevent protein degradation. Care was taken to avoid any contamination with blood during the cannulation of the common bile duct. Moreover, to avoid a possible leakage of plasma proteins into the PJ, all experiments were limited in duration to $75 \mathrm{~min}$. At that time, a blood sample was taken from the inferior cava vein with a heparinized syringe, centrifuged and its plasma fraction recovered.

\section{Immunocytochemistry and confocal microscopy}

The rats were anaesthetized with an intraperitoneal injection of pentobarbital $(40 \mathrm{mg} / \mathrm{kg})$. Pieces of the splenic portion of the pancreas were taken, mounted on tissue-tek O.C.T. (Sakura Finetek Europe, Zoeterwoude, The Netherlands) and immediately frozen in isopentane prechilled with liquid nitrogen. Samples were stored at $-80{ }^{\circ} \mathrm{C}$ or directly transferred to a cryostat where sections $\left(8-10 \mu \mathrm{m}\right.$ thick) were cut at $-20^{\circ} \mathrm{C}$ and mounted on Silane-prep slides (Sigma Diagnostics, Milan, Italy). Sections were air-dried, fixed with cold acetone $\left(-20^{\circ} \mathrm{C}\right)$ for $10 \mathrm{~min}$, and either directly processed for immunocytochemical procedures or stored at $-80{ }^{\circ} \mathrm{C}$ until use.

Slides were incubated with $0.01 \mathrm{M}$ phosphate-buffered saline (PBS), followed by $3 \% \mathrm{H}_{2} \mathrm{O}_{2}$ for $10 \mathrm{~min}$ to inactivate endogenous peroxidase and, after quenching with $10 \%$ goat serum, incubated with rabbit anti-Agt antibody (overnight at $4{ }^{\circ} \mathrm{C}$ at a $1: 100$ dilution). After rinsing with PBS, sections were quenched with $10 \%$ goat serum and incubated with a 1:50 dilution of a secondary antibody to rabbit $\operatorname{IgG}$ (kindly provided by Professor G Lungarella, Department of Physiopathology and Experimental Medicine, University of Siena, Italy). After washing with PBS, slides were finally incubated with a 1:200 dilution of rabbit peroxidase-antiperoxidase complex (Sigma-Aldrich, Milan, Italy) and rinsed in PBS. Immunoreactive cells were visualized with a chromogenic peroxidase substrate consisting of a $0 \cdot 06 \%(\mathrm{w} / \mathrm{v})$ solution of diaminobenzidine in $0 \cdot 05 \mathrm{M}$ Tris/ $\mathrm{HCl}(\mathrm{pH} 7 \cdot 6)$ and $0 \cdot 1 \%$ (v/v) of a $30 \% \mathrm{H}_{2} \mathrm{O}_{2}$ stock solution.

The specificity of the immunohistochemical stain was verified by leaving out the primary antibody and by using it after it had been preadsorbed with angiotensinogen-rich serum from nephrectomized rats, as described previously (Thomas \& Sernia 1988).

For glucagon-Agt double-labelling experiments, sections were quenched with $0 \cdot 1 \%$ bovine serum albumin and incubated with the following sequence of antibodies: guinea pig anti-glucagon ( $3 \mathrm{~h}$ at a 1:100 dilution), FITC-conjugated anti-guinea pig $\operatorname{IgG}(90 \mathrm{~min}$ at a $1: 100$ dilution), rabbit anti-Agt (overnight at a 1:100 dilution) 
and TRITC-conjugated anti-rabbit IgG $(3 \mathrm{~h}$ at a 1:50 dilution).

For insulin-Agt double-labelling experiments, sections were quenched as above and incubated with the following sequence of antibodies: guinea pig anti-insulin $(24 \mathrm{~h}$ at a 1:10 dilution), FITC-conjugated anti-guinea pig $\operatorname{IgG}$ (90 min at a 1:100 dilution), rabbit anti-Agt (overnight at a 1:100 dilution) and TRITC-conjugated anti-rabbit IgG (3 $\mathrm{h}$ at a 1:50 dilution).

For insulin/glucagon (a mixture of guinea pig antiinsulin and anti-glucagon antibodies)-Agt double-staining experiments, sections were quenched as above and incubated with the following sequence of antibodies: guinea pig anti-insulin (24 h at a 1:10 dilution), guinea pig anti-glucagon (3 $\mathrm{h}$ at a 1:100 dilution), FITC-conjugated anti-guinea pig $\operatorname{IgG}(90 \mathrm{~min}$ at a 1:100 dilution), rabbit anti-Agt (overnight at a 1:100 dilution) and TRITCconjugated anti-rabbit $\operatorname{IgG}(3 \mathrm{~h}$ at a 1:50 dilution). Slides were observed with a Leica laser scanning confocal microscope TCS 4D.

\section{Electron microscopy immunocytochemistry}

Agt was detected by using the immunogold method. Rat pancreatic tissue was fixed by immersion with $4 \%$ paraformaldehyde in $0.1 \mathrm{M}$ phosphate buffer. After $4 \mathrm{~h}$ of fixation, the tissue was immediately washed, dehydrated and processed for embedding in Lowicryl K4 M (Chemische Werke Lowi GmbH, Waalskrailburg, Germany) as previously described (Bendayan 1995). Thin tissue sections containing areas of islets of Langerhans were quenched with $1 \%$ ovalbumin for $30 \mathrm{~min}$ and incubated with the rabbit anti-Agt antibody (1:50, overnight at $4{ }^{\circ} \mathrm{C}$ ). Following a rinse with PBS the tissue sections were incubated for 30 min with the protein A-gold complex at room temperature. The protein A-gold was prepared with $10 \mathrm{~nm}$ gold particles as described previously (Bendayan 1995). Sections were stained with uranyl acetate prior to examination with a Philips electron microscope.

\section{SDS-PAGE, isoelectric focusing and Western blotting}

Protein content of plasma and PJ was determined with the microBCA protein assay reagent kit (Pierce, Rockford, IL, USA). Samples were then stored at $-80{ }^{\circ} \mathrm{C}$ until used. Plasma and PJ samples were mixed with Laemmli's sample buffer, boiled for $5 \mathrm{~min}$, centrifuged at $14000 \mathrm{~g}$ for $5 \mathrm{~min}$ and run through a 10\% SDS-PAGE for $2 \mathrm{~h}$.

Denaturating isoelectric focusing (IEF) gels, containing $8 \mathrm{M}$ urea, were prepared according to Robertson et al. (1987) with a combination of ampholyte solutions (Fluka, Milan, Italy) resulting in final concentrations of $0.4 \%(\mathrm{pH}$ range $3 \cdot 5-10)$ and $2 \%(\mathrm{pH}$ range $4-6)$. PJ and plasma were loaded into the wells mixed with the denaturing loading buffer (8 M urea, 2\% Triton X-100, 1\% 2mercaptoethanol, $1 \%$ bromophenol blue, $0 \cdot 4 \%$ ampholyte solution, $\mathrm{pH} 3 \cdot 5-10$ and $2 \%$ ampholyte solution, $\mathrm{pH} 4-6$ ) according to a ratio proportional to the protein content of the samples. Electrophoresis of both samples was run in parallel at room temperature for $30 \mathrm{~min}$ at $150 \mathrm{~V}$ and for a further $3 \mathrm{~h}$ at a constant voltage of $200 \mathrm{~V}$ in a vertical electrophoretic cell (Miniprotean 3; BioRad Laboratories, Segrate, Milan, Italy).

SDS-PAGE and IEF gels were equilibrated in transfer buffer and proteins were transferred onto nitrocellulose membranes with a semidry transblot system (BioRad Laboratories), blocked for $2 \mathrm{~h}$ with 5\% skimmed milk dissolved in Tris-buffered saline (TBS), and incubated overnight with anti-Agt antiserum diluted 1:6000 in TBS with 5\% skimmed milk. Membranes were washed three times with $0 \cdot 1 \%$ Tween-20 in TBS and immunoreactive bands were revealed using a chemiluminescence Western blotting kit (Roche Diagnostics, Monza, Italy). Here, again, control experiments to assess specificity of results consisted of omitting the primary antibody or pre-adsorption with nephrectomized rat serum.

\section{Densitometry}

Images for densitometric evaluations were acquired from Western blots of SDS-PAGE electrophoresis with a GS690 BioRad Imaging densitometer (BioRad Laboratories) and were analysed with molecular analyst $2 \cdot 1$ software (BioRad Laboratories). In order to compare the amounts of Agt present in PJ and in plasma, the software generated a standard curve using three Agt immunoreactive bands corresponding to increasing dilutions of plasma samples. For this purpose, protein content of plasma samples loaded into SDS-PAGE wells were $1 \cdot 25 \mu \mathrm{g}(100 \%), 0 \cdot 625 \mu \mathrm{g}$ $(50 \%)$ and $0.312 \mu \mathrm{g}(25 \%)$ whereas the amount of PJ proteins had to be eightfold higher $(10 \mu \mathrm{g})$ than plasma samples to allow detection of Agt-immunoreactive bands.

\section{Results}

\section{Western blotting and IEF}

Western blot analysis of samples from eight animals carried out with the anti-Agt antibody on plasma proteins separated by SDS-PAGE revealed two major bands with a relative mobility of 58 and $64 \mathrm{kDa}$ whereas PJ samples displayed only one major band co-migrating with the $64 \mathrm{kDa}$ band of the plasma (Fig. 1).

In order to quantify the amounts of Agt present in the PJ, we compared them with plasma Agt. Densitometric analysis of PJ samples from three animals, resulted in an average of $21 \cdot 4 \pm 11.5 \%$ (means \pm S.E.M.) of the amounts found in plasma loaded onto the same gel (Fig. 1). Since quantities of plasma proteins loaded into the wells were eightfold less, the real amounts of Agt in PJ, corrected for 


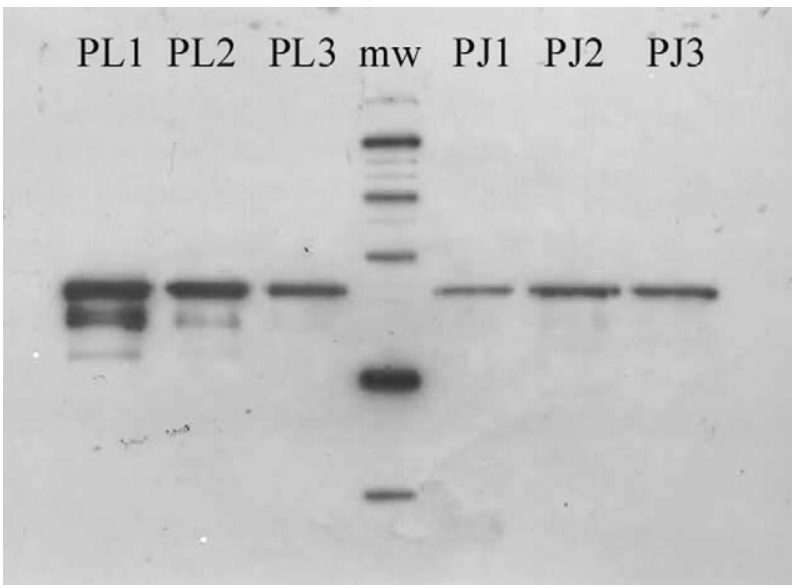

Figure 1 Western blotting with anti-Agt antibody of SDS-PAGE. Lanes 1-3 (PL1-3): different dilutions of the same plasma sample (PL3, $1.25 \mu$ g proteins; PL2, 0.75 $\mu$ g proteins; PL1, 0.312 $\mu \mathrm{g}$ proteins). Lanes 5-7 (PJ1-3): PJ samples from three animals (10 $\mu \mathrm{g}$ proteins/lane). Lane 4: molecular weight standards (37, 50, 75, 100 and $150 \mathrm{kDa})$. PJ samples display only one major band co-migrating with the $64 \mathrm{kDa}$ band of the plasma. This experiment served for the densitometric evaluation of Agt content (see Materials and Methods).

this dilution factor, correspond to $2 \cdot 67 \pm 1 \cdot 43 \%$ of those in the plasma. Starting from the average concentration of plasma Agt, about $0 \cdot 6-1 \mu \mathrm{M}$ depending on rat strain (Hingenfeldt \& Schott 1987), the average molecular weight of Agt $(61 \mathrm{kDa})$, the total concentration of proteins in PJ $(21.58 \pm 2.49 \mathrm{mg} / \mathrm{ml})$ and in plasma $(72 \cdot 27 \pm 0.22 \mathrm{mg} / \mathrm{ml})$ as determined soon after their sampling, and the different quantities of Agt detected in plasma and PJ by densitometry $(10 \mu \mathrm{g}$ PJ proteins having $21.4 \pm 11.5 \%$ of the amount of Agt contained in $1.25 \mu \mathrm{g}$ plasma proteins), it was possible to estimate the average concentrations of Agt in the PJ as being between 5 and $8 \mathrm{nM}$.

To ascertain whether PJ and plasma Agt are secreted as analogue isoforms, IEF analysis of both samples was carried out in parallel. Western blotting with anti-Agt antibodies revealed a slightly different pattern from bands between plasma and PJ Agt. In particular, plasma Agt displayed nine bands as previously reported (Sernia 1995), whereas PJ Agt showed three bands of different pI values (Fig. 2).

\section{Immunocytochemistry and confocal microscopy}

In order to identify the Agt-immunoreactive cells that could be responsible for Agt secretion into the PJ, immunocytochemical experiments with anti-Agt antibody were carried out on cryosections of rat pancreas. Agt-immunoreactive cells were clearly recognized as endocrine cells located at the periphery of all islets of Langerhans (Fig. 3). No staining was detected in the duct lining or in acinar cells. A certain degree of immuno-

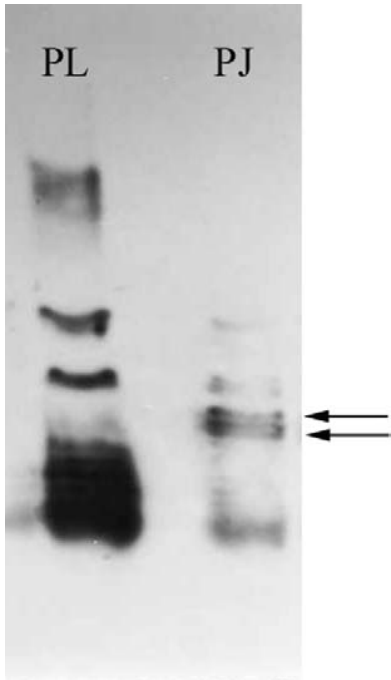

Figure 2 Western blotting with anti-Agt antibody of denaturating IEF gel. PJ displays three bands with very similar pl values (arrows) that are not detectable in plasma $(\mathrm{PL})$.
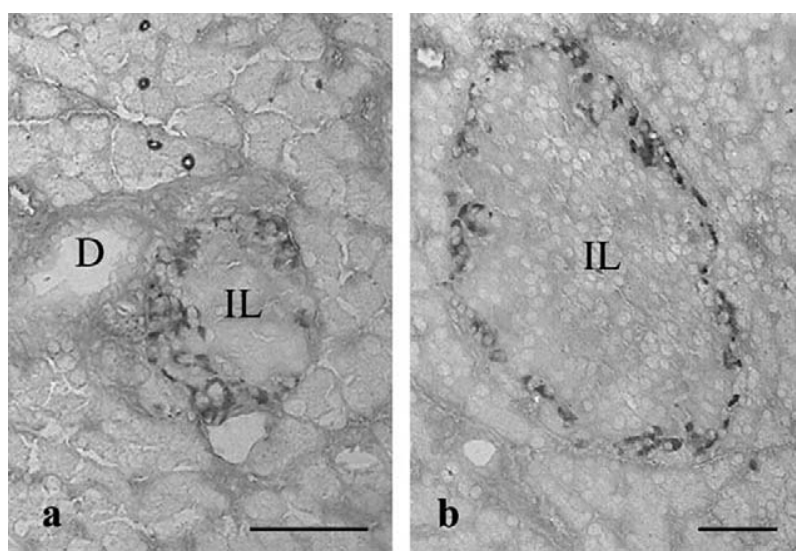

Figure 3 Immunocytochemical detection of Agt-immunoreactive cells in rat pancreas. Agt immunoreactivity is visible exclusively within islet peripheral cells regardless of the size of the islets (middle-sized islet in (a); large islet in (b)). No staining is displayed in duct cells (D). IL=islets of Langerhans. Scale bar $=25 \mu \mathrm{m}$.

reactivity was, however, assigned to the arterial endothelium (data not shown). Control experiments confirmed the specificity of the stainings since no signal was obtained when the primary antibody was omitted or when it was preadsorbed (results not shown).

Agt-immunoreactive cells located at the periphery of the islets closely resembled, in location and in number, glucagon-secreting cells. In order to confirm this observation, double-labelling immunofluorescence experiments were carried out and analyzed by laser scanning confocal microscopy. Sections stained for the simultaneous detection of Agt and glucagon validated that most Agtimmunoreactive cells were indeed glucagon-secreting cells. The reverse was also true since almost all glucagon 

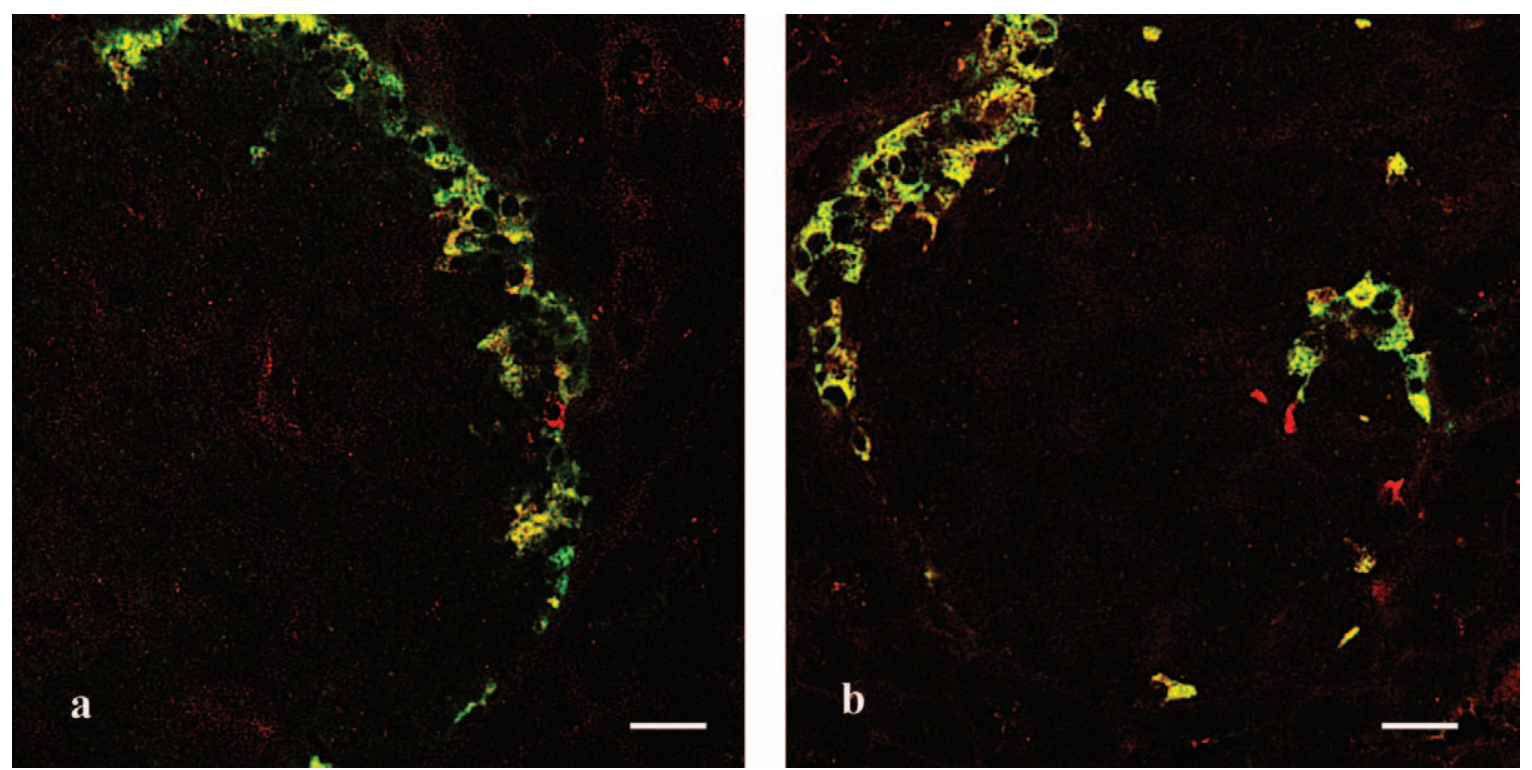

Figure 4 Confocal microscopy of two islets of Langerhans double labelled with anti-Agt (red) and anti-glucagon (green) antibodies. The pattern of staining was essentially the same in all islets of Langerhans as displayed in (a) and (b). Most of the peripheral cells are double labelled (yellow); a few cells, also located at the periphery, display only Agt immunoreactivity. Scale bar $=25 \mu \mathrm{m}$.

cells displayed Agt immunoreactivity. However, a few Agt-immunoreactive cells escaped glucagon staining, raising the possibility that somatostatin or a few peripheral insulin-secreting cells could contain Agt as well (Fig. 4). However, Agt-insulin double-labelling experiments failed to identify cells immunoreactive for both antigens and Agt-insulin/glucagon double-stained sections always displayed Agt-immunoreactive cells that escaped hormone staining (data not shown).

Glucagon/Agt-immunoreactive cells were studied at high magnification to evaluate the pattern of staining within the cells. Even though glucagon and Agt stainings seemed to overlap in consistent regions of the cells, other cytoplasmic areas, characterized by more subtle staining, displayed Agt and glucagon immunoreactivities as segregated in different cellular compartments (Fig. 5).

\section{Transmission electron microscopy}

Using transmission electron microscopy, the immunogold approach revealed Agt antigenic sites in glucagonsecreting cells. The labelling was mainly located in the cytoplasm with preferential location in the rough endoplasmic reticulum. In spite of the relative ultrastructural preservation achieved by the paraformaldehyde fixation required to retain the Agt immunoreactivity, we were able to clearly assign the labelling to small vesicular structures. The classical glucagon-containing secretory granules were devoid of labelling as were mitochondria and nuclei (Fig. 6).

\section{Discussion}

There has been growing interest with regard to pancreatic RAS in the last decade. In order to outline a role for pancreatic RAS, several studies have addressed the expression of each RAS component in the pancreas (Leung \& Carlsson 2001). Intense investigation has focused on the rat pancreas in which all RAS elements were found (Leung et al. 1997, 1999) and Agt was detected within the duct epithelial lining (Leung et al. 1999).

The present study reports Agt immunoreactivity in peripheral islet cells. Duct cells were systematically unstained regardless of the size of the ducts. Confocal microscopy identified most of the Agt-immunoreactive cells as glucagon-secreting cells. Work is in progress to further identify with certainty the few Agtimmunoreactive cells that escaped glucagon staining.

High magnification confocal microscopy of glucagonsecreting cells demonstrated that Agt and glucagon are mostly segregated in different cellular compartments. Cell cytoplasm of glucagon cells appears to be filled with glucagon-immunoreactive tubulovesicular structures and by apparently smaller Agt-immunoreactive structures. Such segregation of both antigens was confirmed by electron microscopy immunocytochemistry, suggesting that glucagon and Agt have different sorting pathways consistent with the notion that glucagon is secreted through the regulated pathway whereas Agt is secreted through the constitutive one (Sernia 1995). 

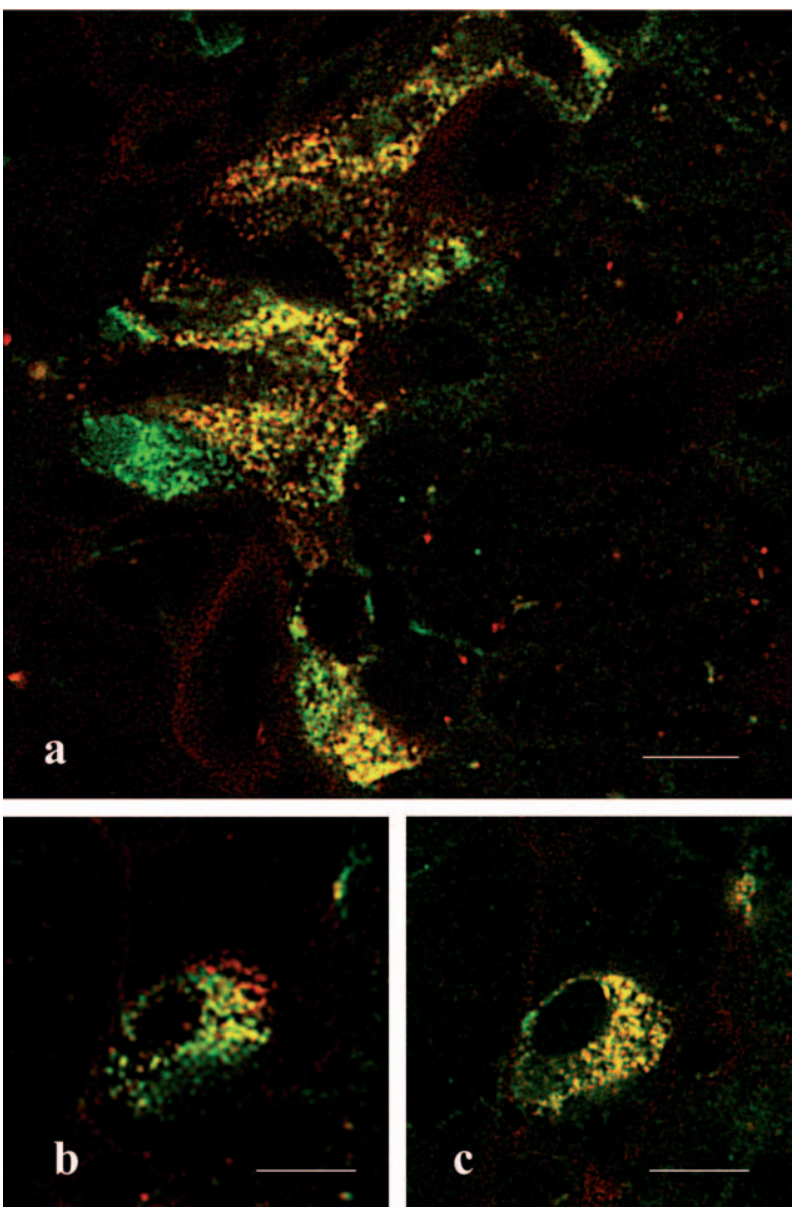

Figure 5 High magnification confocal microscopy of islet peripheral cells double labelled with anti-Agt (red) and anti-glucagon (green) antibodies. (a) Most of the cells display labellings for both antigens. One cell apparently escaped Agt staining. Cytoplasm of Agt/glucagon-immunoreactive cells displays green and red dots. Yellow staining (double-labelled structures) appears to be located where the fluorescent signal is more intense for both antigens. ( $b$ and c) Images of a cell scanned through two different planes. The cytoplasm displays areas expressing exclusively Agt immunoreactivity and others exclusively glucagon immunoreactivity. Certain areas with apparent double-labelled organelles (yellow) are also found. Scale bar $=9 \mu \mathrm{m}$.

Our present demonstration of Agt localization within glucagon-secreting cells is consistent with previous studies that reported 'ectopic' expression of Agt in all islet cell lines derived from the rat insulinoma cell line RIN-r (Brasier et al. 1986, Philippe et al. 1987). In addition, Agt mRNA was previously detected by Northern blot and RT-PCR in dog and rat pancreas (Chappell et al. 1991, Leung et al. 1999). If the source of pancreatic Agt mRNA does not include glucagon-secreting cell populations, Agt immunoreactivity in such cells could be explained only by a mechanism of Agt uptake. This possibility, however, appears remote as in vitro studies on pituitary cells incu- bated with ${ }^{125}$ I-Agt failed to demonstrate any detectable uptake (Sernia et al. 1992). Thus, even though the demonstration of Agt mRNA localization in glucagonsecreting cells is required as definitive evidence, taken together, these data strongly point toward a constitutive expression of Agt at least in rat glucagon-secreting cells. If confirmed by mRNA detection, expression and secretion of Agt from glucagon-secreting cells would appear particularly intriguing as Agt gene expression was found to be influenced by circulating glucose and insulin levels in rat immortalized renal proximal tubular cells (Chen et al. 2001). Insulin, in particular, seems to exert its action at the transcriptional level, modifying the expression of DNAbinding proteins to the insulin-responsive element of the 5 '-flanking region of the Agt gene (Chen et al. 2001). These observations, if transferred to Agt-containing pancreatic cells, suggest a so far unexpected involvement of pancreatic RAS in glucose metabolism, probably by acting as a subtle mediator of blood flow and hormone release (Carlsson et al. 1998).

Pancreatic cells likely release Agt into the interstitial fluid to act, once converted into Ang II, in a paracrine fashion. It is thus reasonable to hypothesize an influence on exocrine secretions by the peri-insular acinar tissue, as AT receptors have been detected on acinar cells and on the AR 42J acinar cell line as well (Chappell et al. 1995, Leung et al. 1997). In this regard, the presence of Agt in glucagon-secreting cells and in a few additional as yet unidentified peripheral islet cells could be the result of the favourable situation of these cells which, being located at the border of the islets, are in the ideal location to influence the peri-insular acinar tissue in a paracrine way.

In addition, Agt may also be secreted into the excretory ducts through the multiple connections occurring between the endocrine compartment of the pancreas and the ductal tree (Park \& Bendayan 1992, Bertelli et al. 1994, 2001). This secretion could be favoured by the peripheral location of glucagon-secreting cells, since duct-islet contacts prevalently take place at the edge of the islets (Bertelli et al. 2001). Indeed, we have been able to demonstrate for the first time the presence of Agt in PJ and, even though we cannot exclude minor contributions of Agt from acinar or duct cells (although Agt was not cytochemically detectable in such cell types), the islet origin of Agt should be considered as the main source of PJ Agt. On the other hand, this exocrine secretion of an hormone is not a unique phenomenon since all the other islet hormones have been previously reported in rat PJ (Prinz et al. 1978, Ertan et al. 1981, Bertelli et al. 2001). Moreover, since some endocrine cells are of the open type facing the duct lumen, as previously reported (Park \& Bendayan 1992), they could provide a direct pathway for Agt secretion into the ducts. An accidental plasmatic source for the PJ Agt should be excluded for two reasons: the constant finding of Agt in the PJ from all examined animals which should exclude occasional contaminations; and the different patterns of 


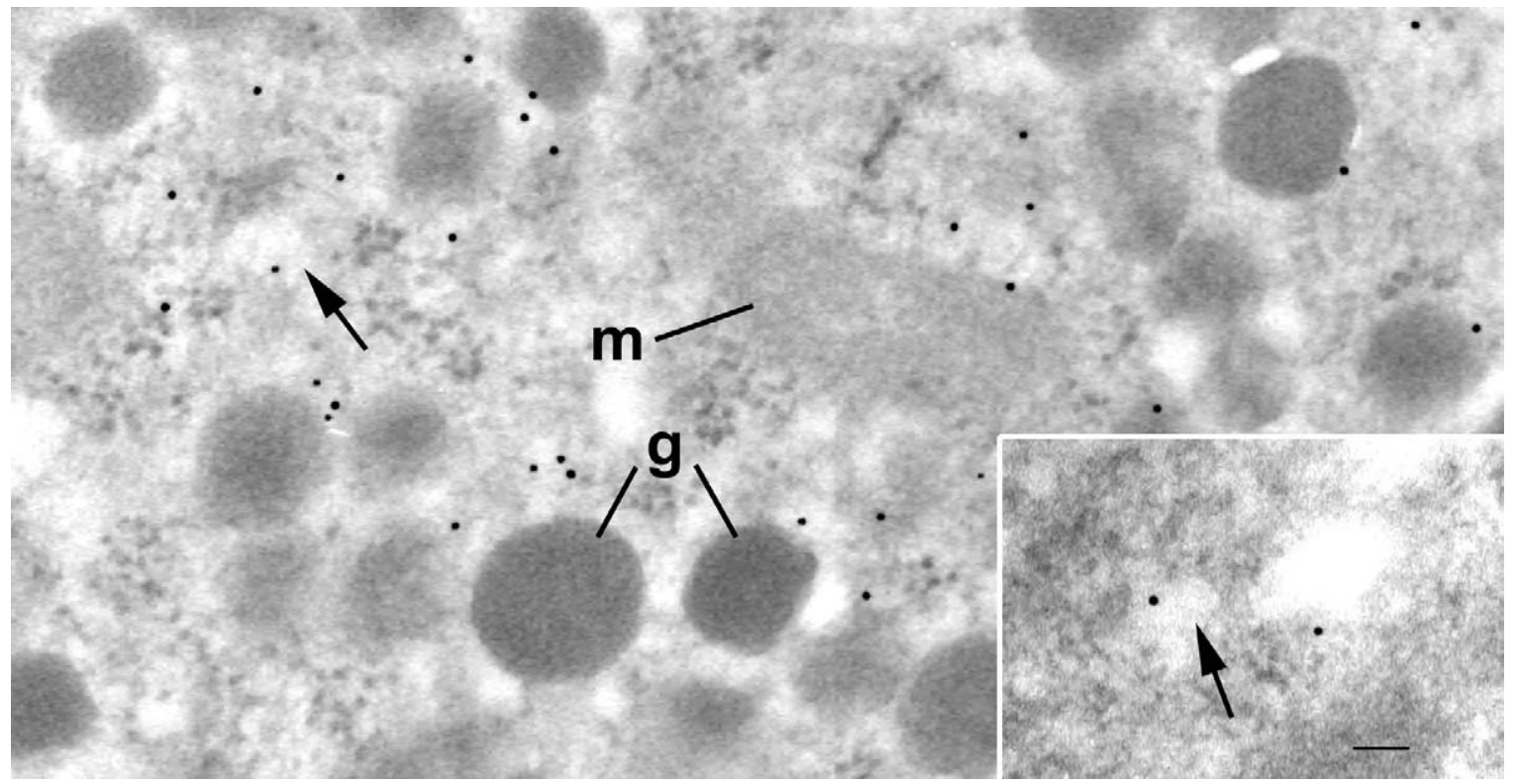

Figure 6 Electron microscopy immunocytochemistry. Thin sections were incubated with the anti-Agt antibody and the protein A-gold complex. The gold particles revealing Agt antigenic sites are located in the cytoplasm among the classical glucagon-containing secretory granules (g). These are devoid of labelling as are the mitochondria (m). Small vesicular structures (arrows) display labelling for Agt. Scale bar $=100 \mathrm{~nm}$.

isoforms identified by IEF occurring between plasma and PJ Agt, demonstrating separate origins.

Since the Agt gene is expressed as just one translational product, pI differences displayed by plasma and PJ Agt are likely due to subtle divergences in post-translational modifications, such as glycosylation. As a matter of fact, differential glycosylation patterns have been previously advocated to explain the heterogeneity of plasma Agt and the variations occurring between plasma and human cerebrospinal fluid Agt as detected by IEF (Genain et al. 1984, Sernia 1995). The functional implication of different Agt post-translational modifications in $\mathrm{PJ}$ is for the moment unknown, but it has been demonstrated that $\mathrm{N}$-glycosylation influences the kinetics of renin Agt reaction (Guimenez-Roqueplo et al. 1998).

To evaluate the importance of Agt secretion in PJ, we have to establish: (i) if Agt is secreted in the PJ in concentrations high enough to exert, upon its conversion into Ang II, a physiological action; (ii) if Agt can be actually converted in Ang II in PJ; and (iii) the roles of PJ Agt under physiological and pathological conditions.

Even though we did not directly determine plasma and PJ Agt concentrations in our rats, the order of magnitude of PJ Agt concentration was roughly assessed on the basis of the average concentration of plasma Agt which is somewhat constant regardless of rat strain (Hingenfeldt \& Schott 1987). Since Agt concentrations in PJ (5-8 nM) are largely above those (from $1 \mathrm{pM}$ to $1 \mathrm{nM}$ ) required for Ang II to elicit a cellular response in several experimental models (Diez de los Rios et al. 1980, Harris \& Navar 1985,
Liu \& Cogan 1988, Geibel et al. 1990, Saccomani et al. 1990), we can assume that Agt present in PJ is indeed sufficient to generate enough Ang II to trigger physiologic actions.

Concerning the feasibility for PJ Agt to be cleaved and generate Ang II, it is well known that the pancreas secretes enzymes capable, under appropriate circumstances, of working in this direction. This is the case for kallikrein (Maruta \& Arakawa 1983) and trypsin (Arakawa et al. 1980) but the family of enzymes able to release Ang II is larger and still growing. Neutrophil serine proteases, such as cathepsin G, elastase, and proteinase 3 , have been recently shown to cleave Agt and release Ang II (Ramaha \& Patston 2002). Due to the high similarities in crystal structure and primary substrate specificities occurring between pancreatic and neutrophil elastases (Bode et al. 1989), it is possible that pancreatic elastase, like neutrophil elastase, may generate Ang II as well. Further studies are, however, required to substantiate this point.

High-affinity binding sites for Ang II have been identified on intestinal epithelium (Cox et al. 1986) but their location referred rather to the basolateral membrane of enterocytes (Cox et al. 1987). Therefore, the most likely target tissue remains the pancreas itself as AT1 and AT2 receptors have been detected on the luminal pole of the duct and acinar cells (Leung et al. 1997). Upon binding to AT1 receptor, Ang II has been shown to increase anion secretion in cystic fibrosis pancreatic duct cells (CFPAC-1), suggesting a possible involvement of pancreatic RAS in the regulation of pancreatic ductal $\mathrm{HCO}_{3}{ }^{-}$secretion (Chan 
et al. 1997). CFPAC-1 responded when Ang II was applied either to the apical or to the basolateral membranes (Chan et al. 1997). However, we should bear in mind that the concentrations of Ang II employed in that study were two to four orders of magnitude higher than those determined in PJ.

In searching for a physiological role for PJ Agt, we should underline that the pancreas appears to be quite enriched in AT2 receptors (Chappell et al. 1992) and that $85 \%$ of all AT receptors in AR42J acinar cells are of the AT2 subtypes (Chappell et al. 1995). Thus, the major actions of Ang II in the pancreas are more likely mediated through its binding to AT2 receptors. Interestingly, signalling mechanisms and the consequent AT2-mediated cell responses are completely different from those elicited upon AT1 activation (De Gaspero et al. 2000, Stoll \& Unger 2001). In particular, AT2 receptors would be heavily involved in cell growth, differentiation and regeneration (Stoll \& Unger 2001). This notion is important as some experimental conditions known to cause mild pancreatitis and/or PJ stasis, like pancreatic duct ligation or its partial obstruction, lead to neogenesis of the endocrine pancreas (Rosemberg 1995, Wang et al. 1995) or induce acinar-islet transdifferentiation (Bertelli \& Bendayan 1997).

It has been suggested that pancreatic RAS is involved in the pathophysiology of pancreatitis (Leung \& Carlsson 2001). Indeed, the recent demonstration that neutrophil serine proteases can generate Ang II (Ramaha \& Patston 2002) and the early recruitment of a large number of granulocytes to the pancreas in the acute phase of pancreatitis (Gorelick et al. 1993, Steer \& Saluja 1993) make PJ Agt a good candidate as a remarkable source of substrate for the generation of Ang II.

\section{Acknowledgements}

This work was supported by 'fondi di liberalità' (L F) and the Canadian Institutes of Health Research (M B). We are indebted to Mr M Losi and D Gingras for their excellent technical support and to Dr L Ermini for his help at the confocal microscope desk.

\section{References}

Arakawa K, Yuki M \& Ikeda M 1980 Chemical identity of tryptensin with angiotensin. Biochemical Journal 187 647-653.

Bendayan M 1995 Colloidal gold post-embedding immunocytochemistry. Progress in Histochemistry and Cytochemistry $291-163$.

Bertelli E \& Bendayan M 1997 Intermediate endocrine-acinar pancreatic cells in duct-ligation condition. American Journal of Physiology 273 C1641-C1649.

Bertelli E, Regoli M \& Bastianini A 1994 Endocrine tissue associated with the pancreatic ductal system: a light and electron microscopic study of the adult rat pancreas with special reference to a new endocrine arrangement. Anatomical Record 239 371-378.
Bertelli E, Regoli M, Orazioli D \& Bendayan M 2001 Association between islets of Langerhans and pancreatic ductal system in adult rat. Where endocrine and exocrine meet together? Diabetologia 44 $575-584$.

Bode W, Meyer E \& Powers JC 1989 Human leukocyte and porcine pancreatic elastase: X-ray crystal structures, mechanism, substrate specificity, and mechanism-based inhibitors. Biochemistry 28 1951-1963.

Brasier AR, Philippe J, Campbell DJ \& Habener JF 1986 Novel expression of the angiotensinogen gene in a rat pancreatic islet cell line. Journal of Biological Chemistry 34 16148-16154.

Campbell DJ 1987 Circulating and tissue angiotensin systems. Journal of Clinical Investigation 79 1-6.

Carlsson PO, Berne C \& Jansson L 1998 Angiotensin II and the endocrine pancreas: effects on islet blood flow and insulin secretion in rats. Diabetologia 41 127-133.

Celio MR 1981 Angiotensin II immunoreactivity coexists with renin in the juxtaglomerular granular cells of the kidney. PNAS $\mathbf{7 8}$ 3897-3900.

Chan HC, Law SH, Leung PS, Fu LXM \& Wong PYD 1997 Angiotensin II receptor type I-regulated anion secretion in cystic fibrosis pancreatic duct cells. Journal of Membrane Biology 156 241-249.

Chappell MC, Millsted A, Diz DI, Brosnihan B \& Ferrario CM 1991 Evidence for an intrinsic angiotensin system in the canine pancreas. Journal of Hypertension 9 751-759.

Chappell MC, Diz DI \& Jacobsen DW 1992 Pharmacological characterization of angiotensin II binding sites in the canine pancreas. Peptides 13 313-318.

Chappell MC, Jacobsen DW \& Tallant EA 1995 Characterization of angiotensin II receptor subtypes in pancreatic acinar AR42J cells. Peptides 16 741-747.

Chen X, Zhang S-L, Pang L, Filep JG, Tang S-S, Ingelfinger JR, Chan JSD 2001 Characterization of a putative insulin-responsive element and its binding protein(s) in rat angiotensinogen gene promoter: regulation by glucose and insulin. Endocrinology 142 $2577-2585$.

Cox HM, Munday KA \& Poat JA 1986 Identification of selective, high affinity $\left[{ }^{125} \mathrm{I}\right]$-angiotensin and $\left[{ }^{125} \mathrm{I}\right]$-bradykinin binding sites in rat intestinal epithelia. British Journal of Pharmacology 87 201-209.

Cox HM, Cuthbert AW \& Munday KA 1987 The effect of angiotensin II upon electrogenic ion transport in rat intestinal epithelia. British Journal of Pharmacology 90 393-401.

Darby IA \& Sernia C 1995 In situ hybridization and immunocytochemistry of renal angiotensinogen in neonatal and adult rat kidney. Cell and Tissue Research 281 197-206.

De Gaspero M, Catt KJ, Ingami T, Wright JW \& Unger Th 2000 International union of pharmacology. XXIII. The angiotensin II receptors. Pharmacological Reviews 52 415-472.

Diez de los Rios A, Labajos M, Manteca A, Morell M \& Souviron A 1980 Stimulatory action of angiotensin II on water and electrolyte transport by the proximal colon of the rat. Journal of Endocrinology 86 35-43.

Dostal DE 2000 The cardiac renin-angiotensin system: novel signaling mechanisms related to cardiac growth and function. Regulatory Peptides 91 1-11.

Ertan A, Taminato T \& Akdamar K 1981 Immunoreactive somatostatin in human pancreatic secretion. Journal of Clinical Endocrinology and Metabolism 52 589-591.

Geibel J, Giebisch G \& Boron WF 1990 Angiotensin II stimulates both $\mathrm{Na}^{+}-\mathrm{H}^{+}$exchange and $\mathrm{Na}^{+} / \mathrm{HCO}_{3}{ }^{-}$cotransport in the rabbit proximal tubule. PNAS 87 7917-7920.

Genain C, Bouhnik J, Tewksbury D, Corvol P \& Menard J 1984 Characterization of plasma and cerebrospinal fluid human angiotensinogen and des-angiotensinI-angiotensinogen by direct radioimmunoassay. Journal of Clinical Endocrinology and Metabolism 59 478-484. 
Gorelick FS, Adler G \& Kern HF 1993 Cerulein-induced pancreatitis. In The Pancreas Biology, Pathobiology, and Disease, pp 501-526. Eds VLW Go, EP DiMagno, JD Gardner, E Lebenthal, HA Reber \& GA Scheele. New York: Raven Press.

Guimenez-Roqueplo A-P, Célérier J, Lucarelli G, Corvol P \& Jeunemaitre X 1998 Role of N-glycosylation in human angiotensinogen. Journal of Biological Chemistry 273 21232-21238.

Hackenthal E, Paul M, Ganten D \& Taugner R 1990 Morphology, physiology, and molecular biology of renin secretion. Physiological Reviews 70 1067-1116.

Harries PJ \& Navar LG 1985 Tubular transport responses to angiotensin. American Journal of Physiology 248 F621-F630.

Hingenfeldt U \& Schott R 1987 Differences in pattern of plasma angiotensinogen in native and nephrectomized rats. Hypertension $\mathbf{9}$ 339-344.

Hunt MK, Ramos SP, Geary KM, Norling LL, Peach MJ, Gomez A \& Carey RM 1992 Colocalization and release of angiotensin and renin in renal cortical cells. American Journal of Physiology 263 F363-F373.

Leung PS \& Carlsson PO 2001 Tissue renin-angiotensin system: its expression, localization, regulation and potential role in the pancreas. Journal of Molecular Endocrinology 26 155-164.

Leung PS, Chan HC, Fu LXM \& Wong PYD 1997 Localization of angiotensin II receptor subtypes AT1 and AT2 in the pancreas of rodents. Journal of Endocrinology 153 269-274.

Leung PS, Chan HC \& Wong PYD 1998 Immunocytochemical localization of angiotensin II in the mouse pancreas. Histochemical Journal 30 21-25.

Leung PS, Chan WP, Wong TP \& Sernia C 1999 Expression and localization of the renin-angiotensin system in the rat pancreas. Journal of Endocrinology 160 13-19.

Liu F-Y \& Cogan MG 1988 Angiotensin II stimulation of hydrogen ion secretion in the rat early proximal tubule: modes of action, mechanism and kinetics. Journal of Clinical Investigation 82 601-607.

Maruta H \& Arakawa K 1983 Confirmation of direct angiotensin formation by kallikrein. Biochemical Journal 213 193-200.

Mulrow PJ \& Franco-Saenz R 1996 The adrenal renin-angiotensin system: a local hormonal regulator of aldosterone production. Journal of Hypertension 14 173-176.

Park I-S \& Bendayan M 1992 Characterization of the endocrine cells in the pancreatic-bile duct system of the rat. Anatomical Record 232 247-256.

Peach MJ 1977 Renin-angiotensin system: biochemistry and mechanisms of action. Physiological Reviews 57 313-370.

Philippe J, Chick WL \& Habener JF 1987 Multipotential phenotypic expression of genes encoding peptide hormones in rat insulinoma cell lines. Journal of Clinical Investigation 79 351-358.

Phillips MI, Speakman EA \& Kimura B 1993 Levels of angiotensin and molecular biology of the tissue renin angiotensin systems. Regulatory Peptides 43 1-20.

Prinz RA, Kokal WA, Kistein L, Smith M, Lawrence AM \& Paloyan E 1978 Presence of high concentrations of glucagon and insulin in pancreatic exocrine secretions. Surgical Forum 29 460-461.
Ramaha A \& Patston PA 2002 Release and degradation of angiotensin II from angiotensinogen by neutrophil serine proteinases. Archives of Biochemistry and Biophysics 397 77-83.

Reid IA, Morris BJ \& Ganong WF 1978 The renin-angiotensin system. Annual Review of Physiology 40 377-410.

Robertson EF, Dannelly HK, Malloy PJ \& Reeves HC 1987 Rapid isoelectric focusing in a vertical polyacrylamide minigel system. Analytical Biochemistry 167 290-294.

Rosemberg L 1995 In vivo transformation: neogenesis of beta cells from pancreatic ductal cells. Cell Transplantation 4 371-383.

Saccomani G, Mitchell KD \& Navar LG 1990 Angiotensin II stimulation of $\mathrm{Na}^{+}-\mathrm{H}^{+}$exchange in proximal tubule cells. American Journal of Physiology 258 F1188-F1195.

Sernia C 1995 Location and secretion of brain angiotensinogen. Regulatory Peptides 57 1-8.

Sernia C, Shinkel TA, Thomas WG, Ho KK \& Lincoln D 1992 Angiotensinogen secretion by single rat pituitary cells: detection by a reverse haemolytic plaque assay and cell identification by immunocytochemistry. Neuroendocrinology 55 308-316.

Steer ML \& Saluja AK 1993 Experimental acute pancreatitis: studies of the early events that lead to cell injury. In The Pancreas Biology, Pathobiology, and Disease, pp 489-500. Eds VLW Go, EP DiMagno, JD Gardner, E Lebenthal, HA Reber \& GA Scheele. New York: Raven Press.

Stoll M \& Unger T 2001 Angiotensin and its $\mathrm{AT}_{2}$ receptor: new insights into an old system. Regulatory Peptides 99 175-182.

Tahmasebi M, Puddefoot JR, Inwang ER \& Vinson GP 1999 The tissue renin-angiotensin system in human pancreas. Journal of Endocrinology 161 317-322.

Tewksbury DA 1983 Angiotensinogen. Federation Proceedings 42 2724-2728.

Thomas WG \& Sernia C 1988 Immunocytochemical localization of angiotensinogen in the rat brain. Neuroscience 25 319-341.

Thomas WG \& Sernia C 1990a Angiotensinogen and angiotensin in the rat pituitary: an immunocytochemical study. Journal of Neuroendocrinology 2 110-118.

Thomas WG \& Sernia C $1990 b$ The immunocytochemical localization of angiotensinogen in the rat ovary. Cell and Tissue Research 261 367-373.

Vinson GP 1995 The adrenal renin/angiotensin system. Advances in Experimental Medicine and Biology 377 237-251.

Vinson GP, Saridogan E, Puddefoot JR \& Djahanbakhch O 1997 Tissue renin-angiotensin systems and reproduction. Human Reproduction 12 651-662.

Wang RN, Klöppel G \& Bouwens L 1995 Duct- to islet-cell differentiation and islet growth in the pancreas of duct-ligated adult rats. Diabetologia 38 1405-1411.

Received 18 March 2003

Accepted 20 June 2003

Made available online as an

Accepted Preprint 25 June 2003 